\title{
Syncope as a presentation of acute pulmonary embolism
}

\author{
This article was published in the following Dove Press journal: \\ Therapeutics and Clinical Risk Management \\ 27 June 2016 \\ Number of times this article has been viewed
}

\section{Bülent Altınsoy \\ Fatma Erboy \\ Hakan Tanriverdi \\ Firat Uygur \\ Tacettin Örnek \\ Figen Atalay \\ Meltem Tor}

Department of Pulmonary Medicine, School of Medicine, Bulent Ecevit University, Kozlu, Zonguldak, Turkey
Correspondence: Bülent Altınsoy

Bülent Ecevit Universitesi Tıp Fakültesi, Göğüs Hastalıkları AD Esenköy, Kozlu,

Zonguldak 67600, Turkey

Tel +905052681060

Fax +903722610155

Email altinsoyb@ymail.com
Purpose: Syncope is an atypical presentation for acute pulmonary embolism (APE). There are conflicting data concerning syncope and prognosis of APE.

Patients and methods: One hundred and seventy-nine consecutive patients aged 22-96 years (median, 68 years) with APE were retrospectively enrolled in the study.

Results: Prevalence of syncope was $13 \%(n=23)$ at the time of presentation. Compared to patients without syncope, those with syncope had a higher rate of central embolism ( $83 \%$ vs $43 \%$, respectively, $P=0.002$ ), right ventricular dysfunction ( $91 \%$ vs $68 \%, P=0.021$ ), and troponin positivity $(80 \%$ vs $39 \%, P=0.001)$ but not 30 -day mortality ( $13 \%$ vs $10 \%, P=0.716)$. Multivariate analysis showed that central localization (odds ratio: 9.08) and cardiac troponin positivity (odds ratio: 4.67) were the independent correlates of the presence of syncope in the patients with APE. Frequency of cardiopulmonary disease was lower, and duration from symptom onset to hospital admission was shorter in patients with syncope $(P=0.138$ and 0.118 , respectively), although not significant.

Conclusion: Syncope most likely represents an intermediate condition between massive APE and hypotension. In APE patients with syncope, the prognosis seems to depend on the underlying pathology, the patient's age, comorbidities and duration from symptom onset to hospital admission, and the use of thrombolytic therapy.

Keywords: syncope, prognosis, pulmonary embolism, mortality rate, compression sonography, right ventricular dysfunction

\section{Introduction}

Acute pulmonary embolism (APE) is a prevalent disease (incidence, 100-200/100,000 inhabitants/yr) with a high mortality rate $(17.4 \%$ for 90 -day mortality rate in unselected population). ${ }^{1}$ Despite advances in treatment and diagnosis, the antemortem diagnosis of fatal PE has not changed markedly for a long time, remaining stable at approximately $30 \%{ }^{2}$ Clinical presentation and the period from onset of symptoms to presentation vary among patients, depending on a number of factors. ${ }^{3}$ The classical symptoms of APE include chest pain, dyspnea, and hemoptysis. Syncope is an atypical symptom of APE and has a reported prevalence of approximately $10 \%$ as the initial presenting sign. ${ }^{4-7}$ There are conflicting data concerning syncope and the prognosis of APE. In earlier studies, the presence of a syncopal episode on presentation of APE was reported to be associated with a high risk of mortality. ${ }^{4,8}$ However, this was not confirmed in later studies. ${ }^{6,9-11}$ Conversely, one paper also suggested that syncope was associated with good prognosis. ${ }^{12}$ It is important to determine whether syncope is associated with poor prognosis to allow prompt risk stratification and appropriate treatment. This study was performed to determine the clinical and prognostic characteristics in patients with syncope in APE. 


\section{Patients and methods}

We retrospectively reviewed the records of 179 consecutive patients with APE admitted to our pulmonary clinic at a tertiary university hospital between January 2013 and May 2015. The study was approved by the Ethics Review Board of Bulent Ecevit University and patient consent was not deemed necessary due to the retrospective nature of the study. APE diagnosis was established by computed tomography pulmonary angiography (CTPA; $\mathrm{n}=136$ ), high probability ventilation/perfusion ( $\dot{\mathrm{V}} / \mathbf{Q})$ scan $(n=41)$, and compression sonography of the leg veins with high clinical probability $(\mathrm{n}=2)$.

Syncope was defined as the sudden, temporary loss of consciousness with spontaneous recovery and without sequelae. The time from the onset of symptoms to hospital admission was defined as presentation time, and earlier presentation was classified as 24 hours or less. Cardiopulmonary disease was defined as the presence of one or more of the following conditions: chronic obstructive pulmonary disease, asthma, coal workers' pneumoconiosis, interstitial lung disease, and heart failure (ejection fraction $\leq 45 \%$ or clinically overt disease). Right ventricular (RV)-to-left ventricular diameter ratio $>1$ on CTPA or pulmonary artery systolic pressure $>30 \mathrm{mmHg}$ on echocardiography was defined as right ventricular dysfunction (RVD). Echocardiographic examination was performed within 5 days of presentation by a cardiologist. Thrombus localization on CTPA was classified as peripheral (isolated lobar, segmental, and/or subsegmental arteries) or central. The shock index was defined as the heart rate divided by systolic blood pressure. Troponin $\mathrm{I}$ and $\mathrm{T}$ were measured at different times (before and after June 2013, respectively). Therefore, statistical analysis was based on troponin positivity instead of continuous values. Troponin $\mathrm{T}$ levels were measured by electrochemiluminescence using the Elecsys e411 analyzer (Roche, Mannheim, Germany). Troponin I levels were measured by chemiluminescence using the Advia Centaur CP (Siemens, Munich, Germany).

\section{Statistical analysis}

Descriptive statistics of the categorical variables are given as numbers or percentages; continuous variables are given as medians (min-max). The chi-square test or Fisher's exact test was used to evaluate categorical variables. The MannWhitney $U$-test was used to compare medians of variables.

Multivariate analysis was performed using logistic regression models with stepwise forward selection to identify independent predictors of syncope in patients with APE. All variables with a $P$-value $<0.20$ in the initial analysis were included in multivariate analysis. The associations are presented as odds ratios (OR) with $95 \%$ confidence intervals (CI). Model discrimination was measured using the area under the receiver operating characteristic curve. Statistical analysis was performed using SPSS Version 18.0 for Windows (SPSS Inc., Chicago, IL, USA). All $P$-values were two-sided, and values less than 0.05 were considered statistically significant.

\section{Results}

The prevalence of syncope at presentation was $13 \%$ in our study population. When age was treated as a dichotomous variable ( $<$ and $\geq 60$ years), a significant difference was observed between these two groups. The patients' clinical characteristics are listed in Table 1. No hemoptysis was seen in patients with syncope. In this study, angina-like pain and pleuritic pain were classified into the same category for chest pain. There was no significant difference between the two groups in terms of chest pain.

A conclusive diagnosis of PE was made by CTPA in 18 (78\%) and by $\dot{V} / \mathbf{Q}$ scan in five (22\%) patients with syncope. In patients with syncope, the thrombus was located centrally $(P<0.001)$. No bradycardia was recorded in patients with syncope. However, heart rate was $<70 \mathrm{bpm}$ in $9 \%(2 / 23)$ of patients with syncope. Hemodynamic deterioration in patients who presented initially in a hemodynamically stable condition was considered an indication for thrombolytic treatment. The frequency of thrombolytic therapy was $17.4 \%$ in the group with syncope and $14.1 \%$ in the group without syncope, and the difference was not significant ( $P=0.751$ ). All patients were given standard anticoagulant therapy, including intravenous unfractionated heparin or subcutaneous low-molecular-weight heparin plus warfarin. The 30-day mortality rate was higher in patients with syncope than in the control group (13\% vs 10\%, respectively); however, the difference between the groups was not statistically significant.

Logistic regression analysis was performed to determine the independent factors associated with the presence of syncope in patients with APE. The following variables were entered into the multivariate analysis: age ( $>60$ years), earlier presentation, cardiopulmonary disease, diabetes, heart rate $(>120 \mathrm{bpm})$, respiratory rate $(>30 / \mathrm{min}), \mathrm{n}(\%)$ cardiac troponin (cTn) positivity, shock index, central localization, and RVD. Multivariate analysis showed that central localization (OR: 9.08) and cTn positivity (OR: 4.67) were independent correlates of the presence of syncope in patients with APE (Table 2). For the final regression model, the goodness of fit of the model was determined to be acceptable using the 
Table I A comparison of presenting characteristics of patients with acute pulmonary embolism with and without syncope

\begin{tabular}{|c|c|c|c|c|}
\hline Variables & $\begin{array}{l}\text { All } \\
(n=179)\end{array}$ & $\begin{array}{l}\text { Without syncope } \\
(n=156)\end{array}$ & $\begin{array}{l}\text { With syncope } \\
(n=23)\end{array}$ & $P$-value \\
\hline \multicolumn{5}{|l|}{ Demographics } \\
\hline Age (years) & $68(22-96)$ & $68(22-96)$ & $60(35-82)$ & 0.152 \\
\hline Age (>60 years), $n(\%)$ & $115(64)$ & $105(67)$ & $10(44)$ & $0.026 *$ \\
\hline Sex (male), n (\%) & $91(51)$ & $78(50)$ & $13(57)$ & 0.559 \\
\hline Earlier presentation, n (\%) & $67(37)$ & $55(35)$ & $12(52)$ & 0.118 \\
\hline Cardiopulmonary disease, n (\%) & $55(3 \mathrm{I})$ & $5 \mathrm{I}(33)$ & $4(17)$ & 0.138 \\
\hline Malignancy, n (\%) & $23(13)$ & $19(12)$ & $4(17)$ & 0.486 \\
\hline Diabetes mellitus, n (\%) & $51(29)$ & $42(27)$ & $9(39)$ & 0.226 \\
\hline Hypertension, n (\%) & $104(58)$ & $91(58)$ & I3 (57) & 0.869 \\
\hline \multicolumn{5}{|l|}{ Symptoms, n (\%) } \\
\hline Dyspnea & $150(84)$ & I32 (85) & $18(78)$ & 0.440 \\
\hline Chest pain & $102(57)$ & $89(57)$ & $13(57)$ & 0.962 \\
\hline Hemoptysis & $18(10)$ & $18(12)$ & $0(0)$ & 0.134 \\
\hline Cough & $4 I(23)$ & $37(24)$ & $4(17)$ & 0.500 \\
\hline \multicolumn{5}{|l|}{ Physical examination, n (\%) } \\
\hline Heart rate $(>\mid 20 \mathrm{bpm})$ & $32(18)$ & $24(15)$ & $8(35)$ & $0.023 *$ \\
\hline $\mathrm{SBP}(<90 \mathrm{mmHg})$ & $4(2)$ & $3(2)$ & I (4) & 0.426 \\
\hline $\mathrm{RR}(>30 / \mathrm{min})$ & $13(8)$ & $8(5)$ & $5(26)$ & $0.008^{*}$ \\
\hline \multicolumn{5}{|l|}{ Laboratory, n (\%) } \\
\hline cTn positivity & $64(45)$ & $48(39)$ & $16(80)$ & $0.001 *$ \\
\hline Shock index & $28(16)$ & $21(14)$ & $7(30)$ & 0.059 \\
\hline Central localization ${ }^{\mathrm{b}}$ & $66(49)$ & $51(43)$ & $15(83)$ & $0.002 *$ \\
\hline RVD & I27 (7I) & $106(68)$ & $2 \mid(9 \mid)$ & $0.02 I^{*}$ \\
\hline 30-day mortality & $19(11)$ & $16(10)$ & $3(13)$ & 0.716 \\
\hline
\end{tabular}

Notes: ${ }^{\mathrm{n}} \mathrm{n}=143,{ }^{\mathrm{b}} \mathrm{n}=136, * \mathrm{P}<0.05$.

Abbreviations: SBP, systolic blood pressure; RR, respiratory rate; $c T n$, cardiac troponin; RVD, right ventricular dysfunction.

Hosmer-Lemeshow test $(P=0.687)$, and the area under the curve was 0.807 (CI, 0.718-0.896) with $P<0.001$.

\section{Discussion}

The prevalence of syncope was $13 \%$ in our study group. This figure was identical to that reported in previous major studies. ${ }^{4,713}$ A central location of the thrombus, troponin positivity, RVD, and increased heart and respiratory rates were more common in patients with syncope. Central thrombus location and troponin positivity were independent factors associated with the presence of syncope.

The classical triad of symptoms of APE includes dyspnea, hemoptysis, and pleuritic chest pain, but many patients are also asymptomatic or have an atypical presentation (syncope, abdominal pain, new onset cardiac arrhythmia, seizure, etc). ${ }^{14-16}$ The diagnosis of APE continues to be difficult due to variability in the clinical picture among patients. It can be difficult to establish the clinical correlation when

Table 2 Multivariate analysis of factors associated with syncope

\begin{tabular}{|c|c|c|c|c|}
\hline Variables & Unadjusted OR $(95 \% \mathrm{CI})$ & $P$-value & Adjusted OR (95\% Cl) & $P$-value \\
\hline Age $(>60$ years $)$ & $0.37(0.15-0.91)$ & $0.030 *$ & & \\
\hline Earlier presentation & $0.50(0.2|-| .21)$ & 0.122 & & \\
\hline Cardiopulmonary disease & $0.43(0.14-1.34)$ & 0.147 & & \\
\hline Diabetes & I.75 (0.70-4.33) & 0.230 & & \\
\hline Heart rate $(>120$ bpm $)$ & $2.93(1.12-7.68)$ & $0.028 *$ & & \\
\hline $\operatorname{RR}(>30 / \min )$ & $6.30(\mid .8 I-21.86)$ & $0.004^{*}$ & & \\
\hline cTn positivity & $6.25(1.97-19.82)$ & $0.002 *$ & $4.67(0.93-23.47)$ & 0.061 \\
\hline Shock index & $2.81(1.04-7.65)$ & $0.043 *$ & & \\
\hline Central localization & 24.67 (3.15-191.24) & $0.002 *$ & 9.08 (1.09-76.04) & $0.042 *$ \\
\hline RVD & $4.95(1.12-21.95)$ & $0.035^{*}$ & & \\
\hline 30-day mortality & $1.31(0.35-4.91)$ & 0.686 & & \\
\hline
\end{tabular}

Note: $* p<0.05$.

Abbreviations: OR, odds ratio; $\mathrm{Cl}$, confidence interval; RR, respiratory rate; $\mathrm{cTn}$, cardiac troponin; RVD, right ventricular dysfunction. 
syncope is the presenting symptom of APE. Syncope seems to be related to central and/or massive APE. ${ }^{4,5}$ If syncope is associated with complete occlusion of the pulmonary blood flow, it progresses to cardiac arrest and death. However, in other cases, syncope is brief and is associated with transient hypotension because occlusion in central pulmonary arteries undergoes partial resolution. This situation results in survival of the patient, and at the same time, it obscures the diagnosis since the blood pressure may have stabilized. ${ }^{4}$ Therefore, it is also interpreted as "forgotten sign" of life-threatening pulmonary embolism. ${ }^{8}$

The three major pathophysiological mechanisms proposed for the development of syncope in APE are acute right heart failure, hemodynamically unstable dysrhythmia (such as bradycardia or tachycardia), and vasovagal reflex. First, occlusion of $>50 \%$ of the pulmonary vascular bed can cause acute RV failure, impaired left ventricular filling, tachycardia, hypotension, and reduced cerebral perfusion. This seems to be the main mechanism responsible for the development of syncope in our study population. With regard to the other mechanisms, there was no electrocardiographic evidence regarding dysrhythmia on presentation. Of course, immediate electrocardiographic, hemodynamic, and echocardiographic examinations after syncope were not possible. The elapsed time between presentation and a syncopal episode may have been responsible for this condition. On the other hand, it should be kept in mind that dysrhythmias may also be the result of APE rather than the primary cause of syncope. None of our patients had a heart rate $<60 \mathrm{bpm}$ or $>150 \mathrm{bpm}$. However, relative bradycardia $(<70 \mathrm{bpm})$ was observed in two of 23 patients $(9 \%)$.

Upon appraisal of the symptoms, there was no difference between the groups in terms of dyspnea. Interestingly, none of the patients with syncope had hemoptysis. Duplyakov et $\mathrm{al}^{17}$ reported similar observations. This condition may result from pulmonary hemorrhage/infarction syndrome associated with minor embolisms occluding the peripheral pulmonary arteries. ${ }^{18}$ There was no difference between the groups in terms of chest pain, and so it was probably due to the classification of angina-like pain and pleuritic pain into a single category for chest pain.

In daily practice, cTnT and cTn I assays are used to diagnose acute coronary syndrome. However, elevated plasma cTnT or cTn I levels can also be observed as the result of transient ischemic or inflammatory myocardial injury in diseases such as pulmonary embolism, severe pulmonary hypertension, heart failure, myocarditis, cardiomyopathies, tachyarrhythmias, renal failure, and sepsis. ${ }^{19}$ In APE, elevated
cTn concentrations are a result of RV ischemia secondary to increased RV wall tension and neurohumoral activation and are associated with increased mortality. ${ }^{20}$ In our study, subjects with syncope had a significantly higher rate of cTn positivity, indicating RV dysfunction.

Syncope in APE patients has generally been considered as an indicator of poor prognosis and has been used as a criterion for thrombolysis in some studies. ${ }^{20-24}$ The circulatory collapse in APE was defined by the presence of shock or syncope (loss of consciousness) in the PIOPED study. ${ }^{2,25}$ Thames et $\mathrm{al}^{4}$ demonstrated significant differences with regard to the pulmonary artery obstruction score $(>50 \%)$ and hemodynamic instability in APE patients with syncope. Konstantinides et $\mathrm{al}^{26}$ showed that the 30-day mortality rate was significantly different between patients with and without syncope in APE (14. 4\% vs 7. 8\%, respectively, $P=0.012) .{ }^{26}$ Similarly, Kumasaka et $\mathrm{al}^{27}$ found that syncope in APE was associated with increased in-hospital mortality (OR: 3.03, $P=0.01) .{ }^{27}$ In the International Cooperative Pulmonary Embolism Registry, the 3-month mortality rate of patients with syncope was $26.8 \%$, whereas the overall mortality rate was $17 \%$. $^{5,13}$

However, several recent studies indicated that syncope is not related to mortality, but is related to hemodynamic instability, ${ }^{9,10,17}$ central or saddle embolism, ${ }^{9,11,17}$ RVD, ${ }^{11,12}$ and troponin positivity. ${ }^{10}$ However, in these studies, the groups with and without syncope differed in age, use of thrombolytics, and comorbidities. Interestingly, Seyyedi et al $^{12}$ reported that syncope in APE is associated with a decreased risk of mortality. The authors stated that these conflicting data may be due to the earlier diagnosis in patients with syncope. In this study, heart failure data were not reported, and RVD (94.7\% vs $72.5 \%$, respectively, $P=0.003$ ), central embolism ( $94.4 \%$ vs $86.0 \%$, respectively, $P=0.195)$, and saddle embolism ( $22.2 \%$ vs $11.5 \%$, respectively, $P=0.104$ ) were more common in patients with syncope compared with the nonsyncope group.

Our results indicated that patients with syncope more commonly present with a centrally located thrombus, RVD, and troponin positivity. However, this condition was not associated with the 30-day mortality rate in our group. There could be several reasons for this observation. The patients with syncope were younger. It seems that age was the most important determinant of prognosis in our study group. In addition, they had less cases of cardiopulmonary disease (17\% vs 33\%) and a shorter duration from symptom onset to hospital admission (probably resulting in prompt treatment), although these differences were not statistically significant. 


\section{Limitations}

This study had some limitations. The design of our study was retrospective. The small number of patients in the syncope group was another factor limiting the interpretation of the results. In addition, the definition of RVD was determined arbitrarily, because both diagnostic procedures (CTPA and echocardiography) were not performed in all patients. Our laboratory switched from measuring troponin I to troponin T during the study; however, previous reports have shown that both troponins have a similar ability to predict the prognoses of APE patients. ${ }^{28}$

\section{Conclusion}

Syncope most likely represents an intermediate condition between massive APE and hypotension. The prognosis seems to depend on the underlying pathology, the patient's age, comorbidities, the duration from symptom onset to hospital admission, and the use of thrombolytic therapy. ${ }^{5}$ In this study, the lack of differences in mortality rate does not eliminate the need for clinicians to remain alert in the management of patients with syncope.

\section{Disclosure}

The authors report no conflict of interest in this work.

\section{References}

1. Bělohlávek J, Dytrych V, Linhart A. Pulmonary embolism, part I: epidemiology, risk factors and risk stratification, pathophysiology, clinical presentation, diagnosis and nonthrombotic pulmonary embolism. Exp Clin Cardiol. 2013;18(2):129-138.

2. Wood KE. Major pulmonary embolism: review of a pathophysiologic approach to the golden hour of hemodynamically significant pulmonary embolism. Chest. 2002;121(3):877-905.

3. Bulbul Y, Ozsu S, Kosucu P, Oztuna F, Ozlu T, Topbaş M. Time delay between onset of symptoms and diagnosis in pulmonary thromboembolism. Respiration. 2009;78(1):36-41.

4. Thames MD, Alpert JS, Dalen JE. Syncope in patients with pulmonary embolism. JAMA. 1977;238(23):2509-2511.

5. Morpurgo M, Zonzin P. Syncope in acute pulmonary embolism. Ital Heart J. 2004;5(1):3-5.

6. Calvo-Romero JM, Pérez-Miranda M, Bureo-Dacal P. Syncope in acute pulmonary embolism. Eur J Emerg Med. 2004;11(4):208-209.

7. Ferrari E, Baudouy M, Cerboni P, et al. Clinical epidemiology of venous thromboembolic disease. Results of a French Multicentre Registry. Eur Heart J. 1997;18(4):685-691.

8. Koutkia P, Wachtel TJ. Pulmonary embolism presenting as syncope: case report and review of the literature. Heart Lung. 1999;28(5): 342-347.

9. Castelli R, Tarsia P, Tantardini C, Pantaleo G, Guariglia A, Porro F. Syncope in patients with pulmonary embolism: comparison between patients with syncope as the presenting symptom of pulmonary embolism and patients with pulmonary embolism without syncope. Vasc Med. 2003;8(4):257-261.
10. Jiménez D, Díaz G, Valle M, et al. Prognostic value of syncope in the presentation of pulmonary embolism. Arch Bronconeumol. 2005; 41(7):385-388.

11. Jenab Y, Lotfi-Tokaldany M, Alemzadeh-Ansari M-J, et al. Correlates of syncope in patients with acute pulmonary thromboembolism. Clin Appl Thromb Hemost. 2015;21(8):772-776.

12. Seyyedi S-R, Jenab Y, Tokaldany ML, Shirani S, Sadeghian S, Jalali A. Syncope paradox in the outcome of patients with pulmonary thromboembolism: short-term and midterm outcome. Clin Respir J. 2016;10(1):90-97.

13. Goldhaber SZ, Visani L, De Rosa M. Acute pulmonary embolism: clinical outcomes in the International Cooperative Pulmonary Embolism Registry (ICOPER). Lancet. 1999;353(9162):1386-1389.

14. Gantner J, Keffeler JE, Derr C. Pulmonary embolism: an abdominal pain masquerader. J Emerg Trauma Shock. 2013;6(4):280-282.

15. Viswanath O, Simpao AF, Santhosh S. Atypical presentation of a pulmonary embolism in the perioperative setting. A A Case Rep. 2015;5(4): 54-56.

16. Ching YH, Alvey EN, Omar HR, Lynch CM, Mangar D, Camporesi EM. Pulmonary embolism presenting as a seizure in the immediate postpartum period. J Obstet Gynaecol. 2015;35(1):92-93.

17. Duplyakov D, Kurakina E, Pavlova T, Khokhlunov S, Surkova E. Value of syncope in patients with high-to-intermediate risk pulmonary artery embolism. Eur Heart J Acute Cardiovasc Care. 2015;4(4):353-358.

18. Stein PD, Henry JW. Clinical characteristics of patients with acute pulmonary embolism stratified according to their presenting syndromes. Chest. 1997;112(4):974-979.

19. Mahajan VS, Jarolim P. How to interpret elevated cardiac troponin levels. Circulation. 2011;124(21):2350-2354.

20. Konstantinides SV, Torbicki A, Agnelli G, et al. 2014 ESC guidelines on the diagnosis and management of acute pulmonary embolism. Eur Heart J. 2014;35(43):3033-3069, 3069a-3069k.

21. Edelson G, Reis ND, Hettinger E. Syncope as a premonitory sign of fatal pulmonary embolism. Two case reports. Acta Orthop Scand. 1988; 59(1):71-73.

22. de Gregorio MA, Gimeno MJ, Alfonso R, et al. Fragmentación mecánica y fibrinólisis intrapulmonar en el tratamiento del tromboembolismo pulmonar masivo con repercusión hemodinámica. [Mechanical fragmentation and intrapulmonary fibrinolysis in the treatment of massive pulmonary embolism hemodynamic repercussions]. Arch Bronconeumol. 2001;37:58-64.

23. De Gregorio MA, Gimeno MJ, Mainar A, et al. Mechanical and enzymatic thrombolysis for massive pulmonary embolism. J Vasc Interv Radiol. 2002;13(2 Pt 1):163-169.

24. Jaber WA, Fong PP, Weisz G, et al. Acute pulmonary embolism: with an emphasis on an interventional approach. J Am Coll Cardiol. 2016; 67(8):991-1002.

25. Stein PD, Terrin ML, Hales CA, et al. Clinical, laboratory, roentgenographic, and electrocardiographic findings in patients with acute pulmonary embolism and no pre-existing cardiac or pulmonary disease. Chest. 1991;100(3):598-603.

26. Konstantinides S, Geibel A, Olschewski M, et al. Association between thrombolytic treatment and the prognosis of hemodynamically stable patients with major pulmonary embolism: results of a multicenter registry. Circulation. 1997;96(3):882-888.

27. Kumasaka N, Sakuma M, Shirato K. Clinical features and predictors of in-hospital mortality in patients with acute and chronic pulmonary thromboembolism. Intern Med. 2000;39(12):1038-1043.

28. Becattini C, Vedovati MC, Agnelli G. Prognostic value of troponins in acute pulmonary embolism: a meta-analysis. Circulation. 2007;116(4): $427-433$. 
Therapeutics and Clinical Risk Management

Dovepress

\section{Publish your work in this journal}

Therapeutics and Clinical Risk Management is an international, peerreviewed journal of clinical therapeutics and risk management, focusing on concise rapid reporting of clinical studies in all therapeutic areas, outcomes, safety, and programs for the effective, safe, and sustained use of medicines. This journal is indexed on PubMed Central, CAS,

EMBase, Scopus and the Elsevier Bibliographic databases. The manuscript management system is completely online and includes a very quick and fair peer-review system, which is all easy to use. Visit http://www.dovepress.com/testimonials.php to read real quotes from published authors.

Submit your manuscript here: http://www.dovepress.com/therapeutics-and-clinical-risk-management-journal 